\title{
Ethyl Docosahexaenoate and Its Acidic Form Increase Bone Formation by Induction of Osteoblast Differentiation and Inhibition of Osteoclastogenesis
}

\author{
Bo-Yun Choi ${ }^{1, a}$, Jae Soon Eun ${ }^{2, a}$, Manoj Nepal', Mi-Kyung Lee ${ }^{2}$, Tae Sung Bae ${ }^{3}$, Byung II Kim ${ }^{4}$ and Yunjo Soh ${ }^{1, *}$ \\ ${ }^{1}$ Department of Dental Pharmacology, School of Dentistry and Institute of Oral Bioscience, Brain Korea 21 Project, \\ Chonbuk National University, Jeonju 561-756, \\ ${ }^{2}$ College of Pharmacy, Woosuk University, Samrye 565-701, \\ ${ }^{3}$ Department of Dental Biomaterials, School of Dentistry, Chonbuk National University, Jeonju 561-756, \\ ${ }^{4}$ Department of Materials Science and Metallurgical Engineering, Sunchon National University, Suncheon 540-742, \\ Republic of Korea
}

\begin{abstract}
Bone remodeling is a dynamic process involving a constant balance between osteoclast-induced bone resorption and osteoblastinduced bone formation. Osteoclasts play a crucial homeostatic role in skeletal modeling and remodeling, and destroy bone in many pathological conditions. Previously, we reported that the hexane soluble fraction of Ficus carica inhibited osteoclast differentiation. Poly unsaturated fatty acids, such as ethyl docosahexaenoate (E-DHA), docosahexaenoic acid (DHA), cis-11,14-eicosadienoic acid (EDA) and eicosapentaenoic acid (EPA), were identified from the hexane soluble fraction of Ficus carica. Among them, E-DHA most potently inhibited osteoclastogenesis in RAW264.7 cells. E-DHA reduced the activities of JNK and NF- $\mathrm{BB}$. E-DHA suppressed the expression of c-Fos and nuclear factor of activated T cells c1 (NFATc1). Interestingly, DHA increased the activity of alkaline phosphatase and expression of bone morphogenetic protein 2 (BMP2) more than E-DHA in MC3T3-E1 cells, suggesting that DHA may induce osteoblast differentiation. The data suggests that a combination of E-DHA and DHA has potential use in the treatment of diseases involving abnormal bone lysis, such as osteoporosis, rheumatoid arthritis and periodontal bone erosion.
\end{abstract}

Key Words: Ethyl docosahexaenoate, Bone formation, RAW264.7 cells, MC3T3-E1 cells, Docosahexaenoic acid

\section{INTRODUCTION}

Long chain polyunsaturated fatty acids (PUFAs) contain at least two double bonds with a minimum chain length of 18 carbons. These long chain PUFAs are incorporated into the cell membranes where they modulate the production of eicosanoids that promote either the inflammatory or anti-inflammatory activities. Although n-3 PUFAs suppress the production of anti-inflammatory cytokines, such as tumor necrosis (TNF) $\alpha$, interleukin (IL)- $1 \beta$ and IL-6, in human and animal models (Meydani et al., 1991; Yaqoob and Calder, 1995; Hudert et al., 2006), n-6 PUFAs tend to stimulate the production of proinflammatory compounds. Proinflammatory signaling is key initiator of bone remodeling. However, chronic inflammation leads to a loss of bone mass and is believed to contribute to the pathogenesis of postmenopausal osteoporosis. The beneficial effect of eicosapentaenoic acid (EPA) and docosahexaenoic acid (DHA) has been demonstrated in several human diseases including atherosclerotic heart disease (Mori and Beilin, 2001), cardiovascular disease (Simopoulos et al., 1991), autoimmune and inflammatory disease like rheumatoid arthritis (Calder and Zurier, 2001) and osteoporosis (Sun et al., 2003; Rahman et al., 2008). Generally, it is believed that the anti-inflammatory activity of $n-3$ long chain PUFAs is responsible for the beneficial effects of long chain PUFAs on bone mass. However, in most studies that reported the bone mass-enhancing effects of long chain PUFAs, a mixture of long chain PUFAs had been administered as the intervention.

Previously, we reported that the hexane soluble fraction of Ficus carica inhibited osteoclast differentiation (Lee, 1996). PUFAs, such as ethyl docosahexaenoate (E-DHA), DHA, cis11,14-eicosadienoic acid and EPA, were identified from the www.biomolther.org

Open Access DOI: 10.4062/biomolther.2011.19.1.070

pISSN: 1976-9148 elSSN: 2005-4483

Copyright $\odot 2011$ The Korean Society of Applied Pharmacology
Received Nov 25, 2010 Revised Dec 31, 2010 Accepted Jan 7, 2011

*Corresponding Author

E-mail:ysoh@jbnu.ac.kr

Tel: +82-63-270-4038, Fax: +82-63-270-4037

'These authors contributed equally to this work. 
hexane soluble fraction of Ficus carica (Park et al., 2009). Although PUFAs have been reported to be involved in bone remodeling, their roles in osteoclastogenesis and osteoblast differentiation are unclear.

Bone remodeling is composed of a balance between osteoclast-induced bone resorption and osteoblast-induced bone formation (Liu et al., 2010; Raggatt and Partridge, 2010). Excessive differentiation of osteoclast cells leads to an imbalance of bone remodeling and causes bone lytic diseases, such as osteoporosis and rheumatoid arthritis (Park et al., 2008). The differentiation of osteoclasts from monocyte/macrophage precursor cells is controlled by two key cytokines, macrophage colony-stimulation factor (M-CSF) and receptor activator of

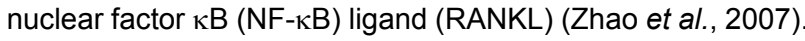
RANKL is essential for precursor cells to differentiate into osteoclasts (Theill et al., 2002; Zhao et al., 2007), whereas the $\mathrm{M}$-CSF secreted by osteoblasts provides the survival signal to these cells (Yoshida et al., 1990). The binding of RANKL to its receptor RANK activates TNF receptor-associated factor 6 (TRAF6), which is linked to nuclear factor $\kappa B(N F-\kappa B)$ and mitogen-activated protein kinases (MAPKs) (Kobayashi et al., 2001; Lee et al., 2002). In addition, RANKL induces the key transcription factor for osteoclastogenesis, nuclear factor of activated T cell c1 (NFATc1) (Takayanagi et al., 2002).

The aim of this study was to determine which PUFA contained in Ficus carica modulate bone remodeling through the inhibition of osteoclastogenesis. The results showed that EDHA inhibits osteoclastogenesis, whereas DHA increases osteoblastic differentiation.

\section{MATERIALS AND METHODS}

\section{Materials}

The cell culture medium and fetal bovine serum (FBS) were obtained from Invitrogen (Gaithersburg, MD, USA). RANKL was obtained from PeproTech (Rocky Hill, NJ, USA). All other chemicals were purchased from Sigma (St. Louis, MO, USA) and unless specified otherwise, are the same as those described elsewhere.

\section{RAW264.7 cell culture and treatment}

The murine RAW264.7 monocyte/macrophage cell line was purchased from the American Type Culture Collection (Manasas, VA, USA) and grown in Dulbecco's Modified Eagle's Medium (DMEM) supplemented with $10 \%$ fetal bovine serum (FBS), $100 \mathrm{U} / \mathrm{ml}$ penicillin and $100 \mu \mathrm{g} / \mathrm{ml}$ streptomycin. All cells were cultured at $37^{\circ} \mathrm{C}$ under a humidified atmosphere counting $5 \% \mathrm{CO}_{2}$. For osteoclastic differentiation, RAW264.7 cells were suspended in $\alpha$-MEM containing 10\% FBS, $100 \mathrm{U} / \mathrm{m}$ penicillin and $100 \mu \mathrm{g} / \mathrm{ml}$ streptomycin. They were then seeded at $3 \times 10^{3}$ cells/well in 96 -well culture plates and cultured with $50 \mathrm{ng} / \mathrm{ml}$ soluble RANKL 6 day (Choi et al., 2010). The cells were stained cytochemically for tartrate-resistant acid phosphatase (TRAP), an osteoclast marker protein (Reddy et al., 1995).

\section{MC3T3-E1 cell culture}

Preosteoblastic MC3T3-E1 cells were grown in $\alpha$-MEM, supplemented with $10 \%$ FBS containing $100 \mathrm{U} / \mathrm{ml}$ penicillin and $100 \mu \mathrm{g} / \mathrm{ml}$ streptomycin in $37^{\circ} \mathrm{C}$ in a humidified atmosphere of $5 \% \mathrm{CO}_{2}$. The cells were treated with trypsin/EDTA, counted and plated in 12-well plates (SPL, Korea). $10 \mathrm{mM} \beta$ glycerophosphate and $50 \mu \mathrm{g} / \mathrm{ml}$ ascorbic acid, with or without MEFC, were added to the media for the indicated times. The culture medium was changed every third day. The cells were then harvested with trypsin, washed three times with PBS and assayed for the alkaline phosphatase activity.

\section{Alkaline phosphatase (ALP) activity}

The ALP activity was measured using the alkaline phosphate yellow liquid substrate in the ELISA kit (Sigma) according to the manufacturer's instructions. Briefly, MC3T3-E1 cells were washed three times with PBS, sonicated with a lysis buffer (50 mM Tris pH 7.4, $150 \mathrm{mM} \mathrm{NaCl}, 1 \mathrm{mM}$ EDTA) and the protein concentration was measured using the Bradford reagent. The reaction was started by the addition of $200 \mu \mathrm{l}$ of para-nitrophenylphosphate (Sigma) to $50 \mu$ of cell lysates, and the reaction mixture was incubated for two hours at $37^{\circ} \mathrm{C}$. $50 \mu \mathrm{l}$ of a $3 \mathrm{~N} \mathrm{NaOH}$ solution was added to quench the reaction, and the absorbance was measured at $405 \mathrm{~nm}$.

\section{MTT assay}

The cells $\left(5 \times 10^{3} /\right.$ well $)$ were seeded in a 96 -well plate and incubated overnight in media supplemented with $10 \%$ FBS. Various concentrations of PUFAs were then added to the cells. The cells were then incubated for $24 \mathrm{~h}$, washed with phosphate-buffered saline (PBS) and treated with a medium containing $100 \mu \mathrm{g} / \mathrm{ml}$ of MTT [3-(4,5-dimethylthiazol-2-yl)-2,5diphenyltetrazolium bromide] for $2 \mathrm{~h}$ at $37^{\circ} \mathrm{C}$. The cells were then washed with PBS and dissolved in $200 \mu \mathrm{l}$ of DMSO. The resulting intracellular purple formazan was quantified from the absorbance at $540 \mathrm{~nm}$ using a spectrophotometer.

Table 1. Primer sequences and conditions for RT-PCR

\begin{tabular}{|c|c|c|c|}
\hline $\begin{array}{c}\text { Target genes } \\
\text { (Accession } \\
\text { Number) }\end{array}$ & Primers (Forward, Reverse) & $\begin{array}{l}\text { Annealing } \\
\operatorname{Tm}\left({ }^{\circ} \mathrm{C}\right)\end{array}$ & $\begin{array}{l}\text { PCR } \\
\text { cycles }\end{array}$ \\
\hline $\begin{array}{l}\text { TRAP } \\
(\text { NM_007388) }\end{array}$ & $\begin{array}{l}\text { 5'-ctgctgggcctacaaatcat-3' } \\
\text { 5'-ggtagtaagggctggggaag-3' }\end{array}$ & 54 & 21 \\
\hline $\begin{array}{l}\text { MMP9 } \\
\text { (NM_013599) }\end{array}$ & $\begin{array}{l}\text { 5'-cgtcgtgatccccacttact-3' } \\
\text { 5'-agagtactgcttgcccagga-3' }\end{array}$ & 57.5 & 30 \\
\hline $\begin{array}{l}\text { c-Fos } \\
(\text { NM_010234) }\end{array}$ & $\begin{array}{l}\text { 5'-atgggctctcctgtcaacac-3' } \\
\text { 5'-ggctgccaaaataaactcca-3' }\end{array}$ & 57.5 & 30 \\
\hline $\begin{array}{l}\text { c-fms } \\
(X 06368)\end{array}$ & $\begin{array}{l}5 \text { '-aggaggtgtctgtgggtgac }-3 \\
5 \text { '-acagtaaggtttccacgttt }-3 \text { ' }\end{array}$ & 55 & 30 \\
\hline $\begin{array}{l}\text { NFATc1 } \\
(\text { NM_010234) }\end{array}$ & $\begin{array}{l}\text { 5'-gggtcagtgtgaccgaagat-3' } \\
\text { 5'-ggaagtcagaagtgggtgga-3' }\end{array}$ & 55 & 30 \\
\hline $\begin{array}{l}\text { BMP-2 } \\
\text { (NM_007553) }\end{array}$ & $\begin{array}{l}\text { 5'-gctccacaaacgagaaaagc-3' } \\
\text { 5'-agcaaggggaaaaggacact-3' }\end{array}$ & 65 & 40 \\
\hline $\begin{array}{l}\text { OCN } \\
\left(N M \_009506\right)\end{array}$ & $\begin{array}{l}\text { 5'-cagcttggtgcacacctagc-3' } \\
\text { 5'-agggttaagctcacactgctcc-3' }\end{array}$ & 65 & 40 \\
\hline $\begin{array}{l}\text { OPG } \\
(\mathrm{MGI}: 109587)\end{array}$ & $\begin{array}{l}\text { 5'-tgctcctggacatcattgaa-3' } \\
\text { 5'-gtgctgcagttcgtgtgttt-3' }\end{array}$ & 65 & 40 \\
\hline $\begin{array}{l}\beta \text {-actin } \\
(\text { NM_007393) }\end{array}$ & $\begin{array}{l}\text { 5'-ttctacaatgagctgcgtgt-3' } \\
\text { 5'-ctcatagctcttctccaggg- }\end{array}$ & 50 & 25 \\
\hline $\begin{array}{l}\text { GAPDH } \\
\text { (NM 008084) }\end{array}$ & $\begin{array}{l}\text { 5'- accacagtccatgccatcac-3' } \\
\text { 5'-tacagcaacagggtggtgga }-3,\end{array}$ & 56 & 30 \\
\hline
\end{tabular}




\section{Tartrate-resistant acid phosphatase (TRAP) staining}

TRAP staining was performed according to the methodology reported by Park et al. (2008). Briefly, the cells were washed with PBS and fixed with $3.7 \%$ formaldehyde for $10 \mathrm{~min}$. After washing with PBS, the cells were incubated with $0.1 \%(\mathrm{v} / \mathrm{v})$ Triton X-100 for $1 \mathrm{~min}$. The cells were washed, and incubated for $40 \mathrm{~min}$ at $37^{\circ} \mathrm{C}$ in the dark with a mixture of Fast Garnet GBC, sodium nitrite, naphthol AS-BI phosphoric acid, acetate, and tartrate solutions in the Leukocyte Acid Phosphatase Assay kit (Sigma) according to the manufacturer's instructions. The cells were washed with distilled water and the number of TRAP-positive multinucleated cells containing three or more nuclei was counted using an optical microscope.

\section{Western blot analysis}

After washing twice with cold PBS, the total cell lysates were prepared by lysing the cell in a cold lysis buffer [50 $\mathrm{mM}$ Tris- $\mathrm{HCl}, 150 \mathrm{mM} \mathrm{NaCl}, 5 \mathrm{mM}$ EDTA, 1\% NP-40, $1 \mathrm{mM}$ phenylmethylsulfonylfluoride (PMSF)]. The total cell lysates were incubated for $10 \mathrm{~min}$ in ice and centrifuged at $12,000 \times \mathrm{g}$ for $20 \mathrm{~min}$ at $4^{\circ} \mathrm{C}$, the supernatants were used as the total cell extracts. The total cell extracts were separated on $8-10 \%$ SDS-PAGE and transferred to a polyvinylidene difluoride (PVDF) membrane (Bio-Rad, Hercules, CA, USA). The membranes were blocked with $5 \%$ skim milk in Tris-buffered saline (TBS) containing $0.1 \%$ Tween-20 (TTBS) at room temperature for $1 \mathrm{~h}$, and then incubated for $16-18 \mathrm{~h}$ at $4^{\circ} \mathrm{C}$ with the specific antibodies diluted 1:1,000 in 5\% skim milk in TTBS.

\section{Reverse transcription-polymerase chain reaction analysis (RT-PCR)}

The total RNA was isolated using the TRIzol reagent (Invitrogen, Carlsbad, CA). cDNA was synthesized by using Superscript II (invitrogen). The PCR primers were purchased from Bioneer (Daejeon, Korea). Table 1 lists the primer sequences and PCR conditions used in this study. After initial denaturation at $94^{\circ} \mathrm{C}$ for $40 \mathrm{sec}, \mathrm{PCR}$ was performed for various cycles using Taq polymerase. The reaction products were separated on $1 \%$ agarose gel, stained with ethidium bromide, and analyzed densitometrically using a Phosphoimager and Quantity One software (Bio-Rad, Hercules, CA, USA).

\section{Statistics analysis}

All experimental data is expressed as the mean \pm S.E.M. All experiments were repeated at least three times, unless otherwise indicated. Statistical analyses were performed using a Dunnett's multiple comparison test in SPSS ver. 12.0 software. $p$-values $<0.05$ were considered significant.

\section{RESULTS}

\section{Effects of E-DHA on osteoclast differentiation in RAW264.7 cells}

The effects of 4 PUFAs, such as E-DHA, DHA, Cis-11, 14-eicosadienoic acid, and EPA on osteoclast differentiation were examined to determine which PUFA inhibits osteoclastogensis most potently in RAW264.7 cells. As shown in Fig. 1A, among the 4 PUFAs tested, E-DHA decreased the maturation of preosteoclast cells most significantly. E-DHA reduced the TRAP-positive multinucleated cells generated with $35.7 \pm$ $3.37 \%, 69.0 \pm 20.0 \%$ and $100 \pm 3.37 \%$ inhibition at $0.001,0.01$

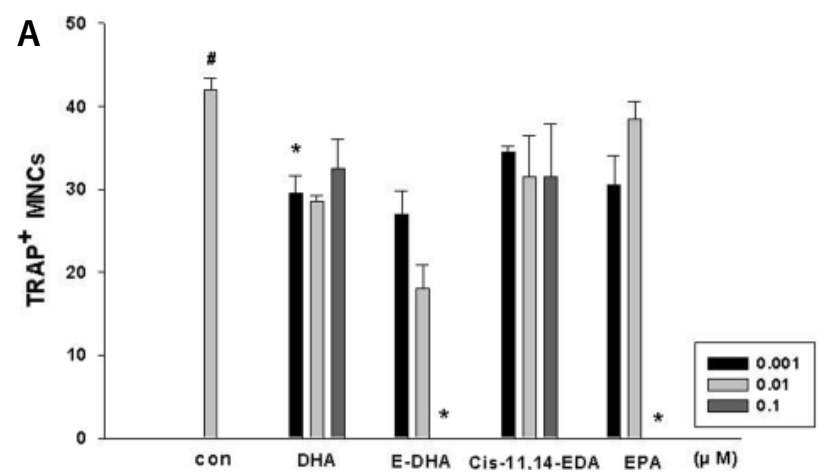

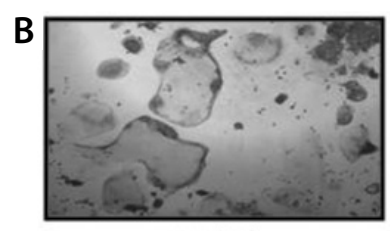

control

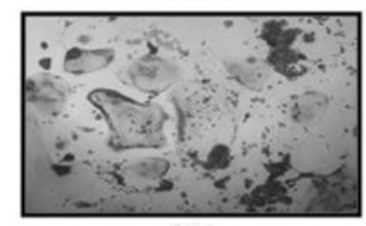

0.01

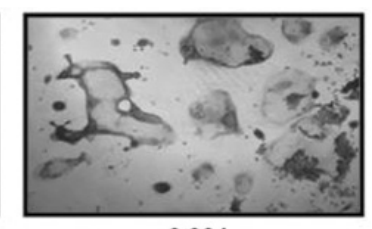

0.001
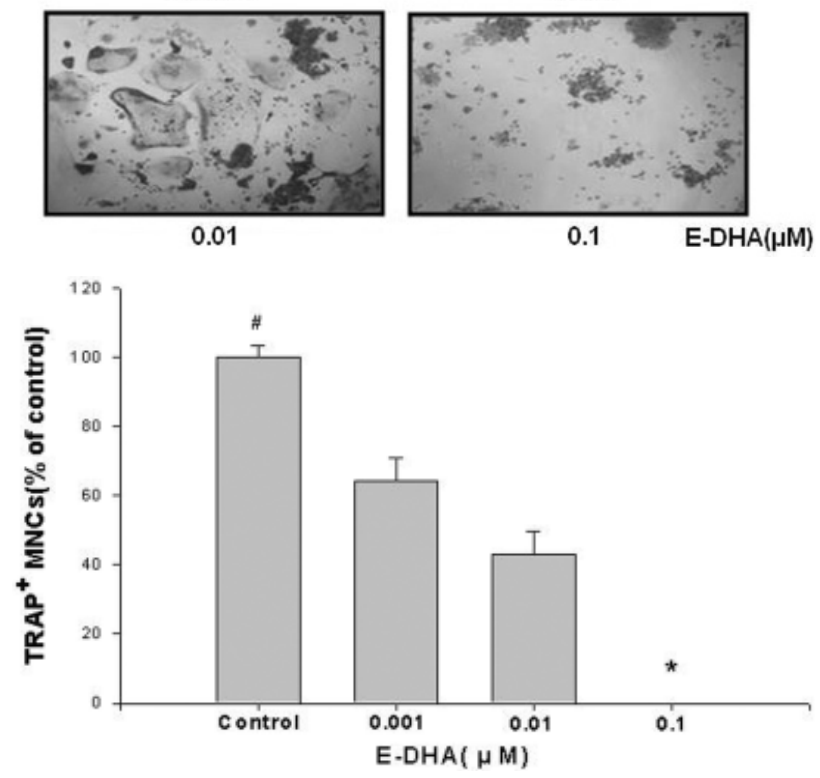

Fig. 1. Inhibitory effects of PUFAs on osteoclast differentiation in RANKL-stimulated RAW 264.7 cells. (A) RAW 264.7 cells were cultured with the indicated concentrations of ethyl docosahexaenoate (E-DHA), docosahexaenoic acid (DHA), cis-11,14-eicosadienoic acid, and eicosapentaenoic acid in the presence of RANKL (50 ng/ $\mathrm{ml})$. After 6 days, the cells were fixed and stained for TRAP. (B) TRAP-positive multinucleated cells $\left(\right.$ TRAP $\left.^{+}\right)$treated with E-DHA for 6 days were counted. (C) The effect of E-DHA on cell viability was measured with MTT assay. The results are expressed as the mean \pm S.E.M. ${ }^{*} p<0.05$ versus vehicle-treated cells (\#).

and $0.1 \mu \mathrm{M}$, respectively (Fig. 1B). To examine the effect of $\mathrm{E}-\mathrm{DHA}$ on cell growth, the cells were treated with various concentrations of E-DHA for $24 \mathrm{~h}$, and cell growth was measured using an MTT assay. E-DHA did not affect the cell growth rate of the RAW264.7 cells (Fig. 1C).

\section{Effects on the activation of MAPKs in RANKL-simulated RAW 264.7 cells}

The role of MAPKs in the RANKL-signaling pathway upon 


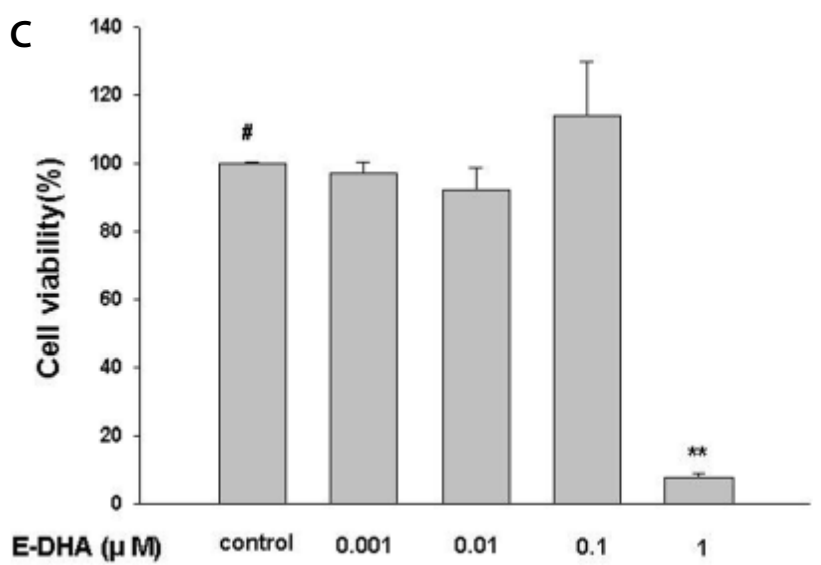

Fig. 1. Continued.

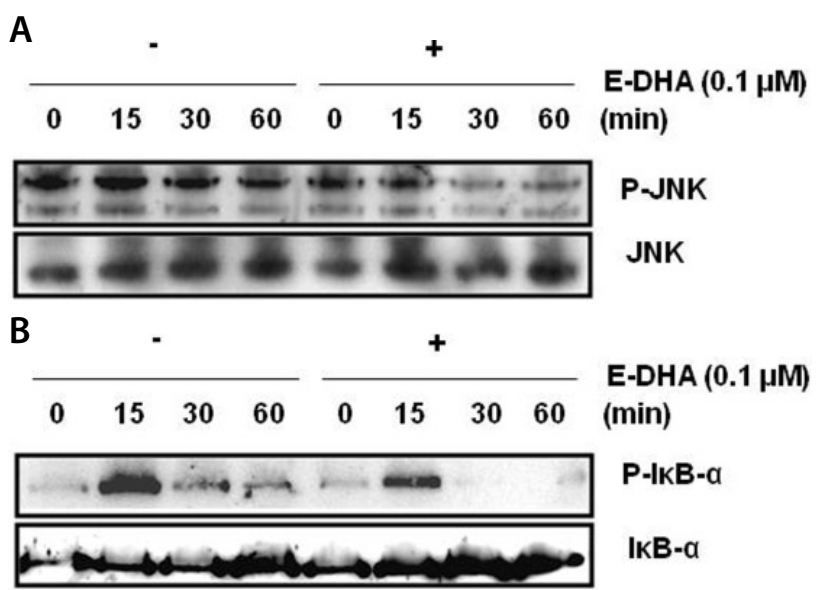

Fig. 2. Effect of E-DHA on JNK (A), and NF-KB (B) activation in RANKL-stimulated RAW 264.7 cells. RAW 264.7 cells were serumstarved for $16 \mathrm{~h}$, pretreated with $0.1 \mu \mathrm{M}$ E-DHA for $30 \mathrm{~min}$ and stimulated with RANKL $(100 \mathrm{ng} / \mathrm{ml})$ for the indicated times. The cell extracts were prepared and analyzed by Western blot using the antibodies specifically to the phosphorylated forms of the enzymes, compared to data obtained with the antibodies directed against the unphosphorylated states of the kinases.

treatment with E-DHA was investigated to determine the intracellular mechanism of E-DHA. The three families of MAPKs, ERK, JNK and p38, participate in RANKL-induced osteoclast differentiation. The activities of JNK, ERK, p38 and Akt were determined by Western blot analysis using the antibodies specifically directed against the phosphorylated forms of the enzymes, compared to the data obtained with the antibodies directed against the unphosphorylated states of the kinases. RANKL-induced JNK phosphorylation was reduced significantly by E-DHA (Fig. 2A). However, ERK, p38 and Akt were not modulated by the E-DHA treatment (data not shown), suggesting that E-DHA acts via the JNK signaling pathway.

\section{Effect of E-DHA on NF- $\kappa$ B activation}

Activation of the NF- $\kappa B$ transcription factor is an essential step for osteoclast differentiation. A recent study suggested that NF- $\mathrm{KB}$ is another upstream transcription factor modulat-

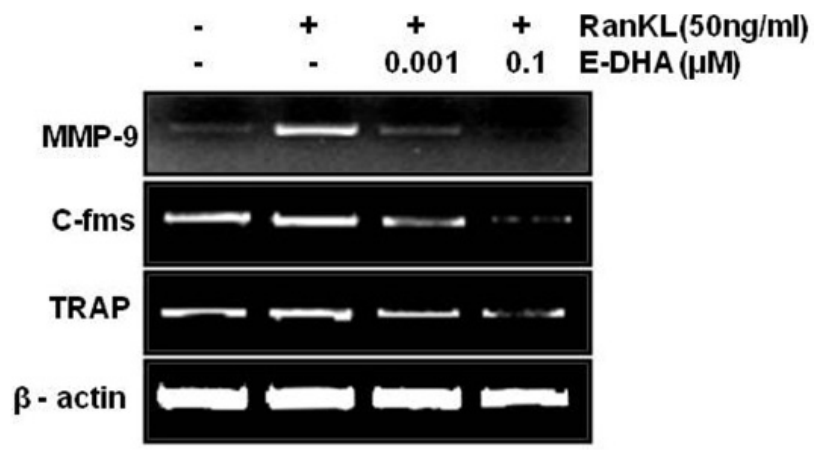

Fig. 3. Suppression of RANKL-induced gene expression by EDHA. (A) RAW264.7 cells were cultured with the indicated concentrations of E-DHA in the presence of RANKL $(50 \mathrm{ng} / \mathrm{ml})$. After 6 days, the mRNA expression levels of MMP9, TRAP and c-fms genes were determined by RT-PCR and compared with that of $\beta$ actin.

ing NFATc1 expression. Therefore, this study examined the effects of E-DHA on the NF- $\kappa B$ pathway. RAW 264.7 cells were stimulated with RANKL in the presence or absence of E-DHA, and the phosphorylation states of $\mathrm{IKB}$ were assessed by Western blotting. As shown in Fig. 2B, $0.1 \mu \mathrm{M}$ E-DHA markedly reduced the RANKL-induced phosphorylation of IKB within 15 $\min$.

\section{Effects of E-DHA on the expression of osteoclast specific genes}

Osteoclast differentiation is associated with the regulation of specific genes in response to RANKL. To examine the alterations of the genes, the total RNAs were prepared and analyzed by RT-PCR. RANKL $(50 \mathrm{ng} / \mathrm{ml})$ induced the expression of MMP-9, TRAP and c-fms in RAW264.7 cells. E-DHA reduced the expression of these osteoclast specific genes in a concentration-dependent manner without changing the housekeeping gene $\beta$-actin (Fig. 3). These results suggest that E-DHA inhibits osteoclastogenesis by suppressing the osteoclast specific genes.

\section{Effect on the expression of c-fos in RANKL-induced RAW264.7 cells}

RANKL increases the c-fos level in osteoclast precursor cells. Therefore, the RANKL-induced level of c-fos mRNA was increased greatly but was reversed by E-DHA in a concentration-dependent manner (Fig. 4).

\section{Effects of 4 PUFAs on the ALP activity during osteoblast differentiation in MC3T3-E1 cells}

The differentiation of MC3T3-E1 cells was induced by a treatment with $\beta$-glycerophosphate and ascorbic acid for the indicated times as described in Materials and Methods. The cells were cultured for $0,3,7,14$, and 21 days in the presence or absence of $0.1 \mu \mathrm{M}$ PUFAs, and equal amounts of proteins were taken to measure the ALP activity at $405 \mathrm{~nm}$. Among the 4 PUFAs, DHA exhibited the highest ALP activity in 2 weeks after culture until 3 weeks (Fig. 5). This suggests that DHA, the de-esterified form of E-DHA, contributes to osteoblast differentiation, whereas E-DHA inhibits osteoclastogenesis. 


\section{Effects of 4 PUFAs on the expression of osteoblast specific genes during the differentiation of MC3T3-E1 cells}

To examine the effects of 4 PUFAs on the expression of osteoblast specific genes, such as BMP2, OCN, and OPG in MC3T3-E1 cells, the total RNA was extracted and analyzed by RT-PCR (Fig. 6). The level of BMP2 mRNA was increased significantly by a treatment with DHA and cis-11, 14-Eicosadienoic acid, whereas E-DHA and EPA decreased the level of BMP2 mRNA compared to the vehicle control. E-DHA and cis11, 14-eicosadienoic acid consistently induced the expression of OPG but DHA and EPA induced it only in the late or early times of differentiation, respectively. OCN was induced slowly by E-DHA. The other PUFAs induced OCN continuously in the differentiation media.

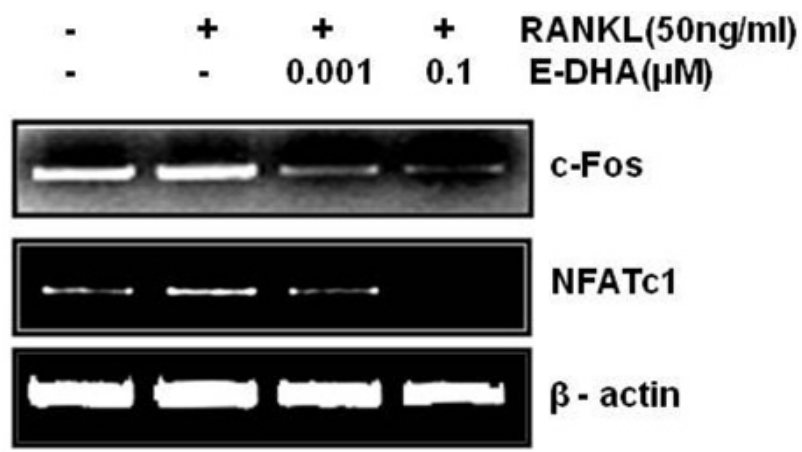

Fig. 4. Suppression of RANKL-induced c-Fos and NFATc1 expression by E-DHA. (A) RAW264.7 cells were cultured with the indicated concentrations of E-DHA in the presence of RANKL (50 ng/ $\mathrm{ml}$ ). After $6 \mathrm{~h}$, the mRNA expression levels of the c-fos genes were determined by RT-PCR and compared with that of $\beta$-actin.

\section{DISCUSSION}

The signaling mechanism of RANKL has been studied extensively. Osteoblast lineage cells express a membranebound form of RANKL, a member of the TNF cytokine family. Like other members of the TNF receptor superfamily, RANK strongly activates the NF- $\mathrm{BB}$ pathway. In the canonical NF$\kappa B$ pathway, the ligation of RANK activates the inhibitor of

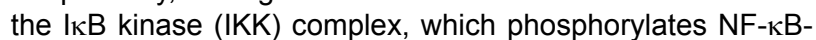
associated $\mathrm{I} \mathrm{KB}$ leading to its ubiquitination and proteosomal degradation. These events release NF- $\kappa B$ dimers containing RelA and c-Rel in the cytosol, allowing them to translocate into the nucleus where they enhance the transcription of the target genes (Luo et al., 2005).

A beneficial effect of DHA on bone mass has previously been suggested after studies compared the effects of mixed fatty acid supplements with different DHA contents (Rahman et al., 2008). In vitro, DHA inhibits the RANKL-induced differentiation of osteoclasts from RAW264.7 cells (Rahman et al., 2008). Rahman et al reported that DHA is a more potent inhibitor of osteoclast differentiation in RAW264.7 cells than eicosapentaenoic acid. However, the inhibitory effects of DHA on mature osteoclasts in vivo might be minimal or transient because no effect of DHA on bone resorption was observed in growing male rats or in ovariectomized (OVX) female rats (Poulsen et al., 2007). Poulsen et al reported a significantly greater lumbar spine bone area of DHA-supplemented animals compared to OVX controls due to an increase in bone formation or a change in the site of bone formation.

Osteoblast differentiation is induced by BMP-2, which belongs to the transforming growth factor- $\beta$ (TGF- $\beta$ ) super family (Tachi et al., 2010a). BMP-2 transduces its signal to the target genes such as ALP, bone sialoprotein, osteocalcin, RUNX2, Dlx5 (Mukherjee et al., 2010) and vitamin D receptor (Otsuka et al., 2003). Although BMP-2 plays a key role in osteoblast differentiation, it has also been suggested to regulate osteo-

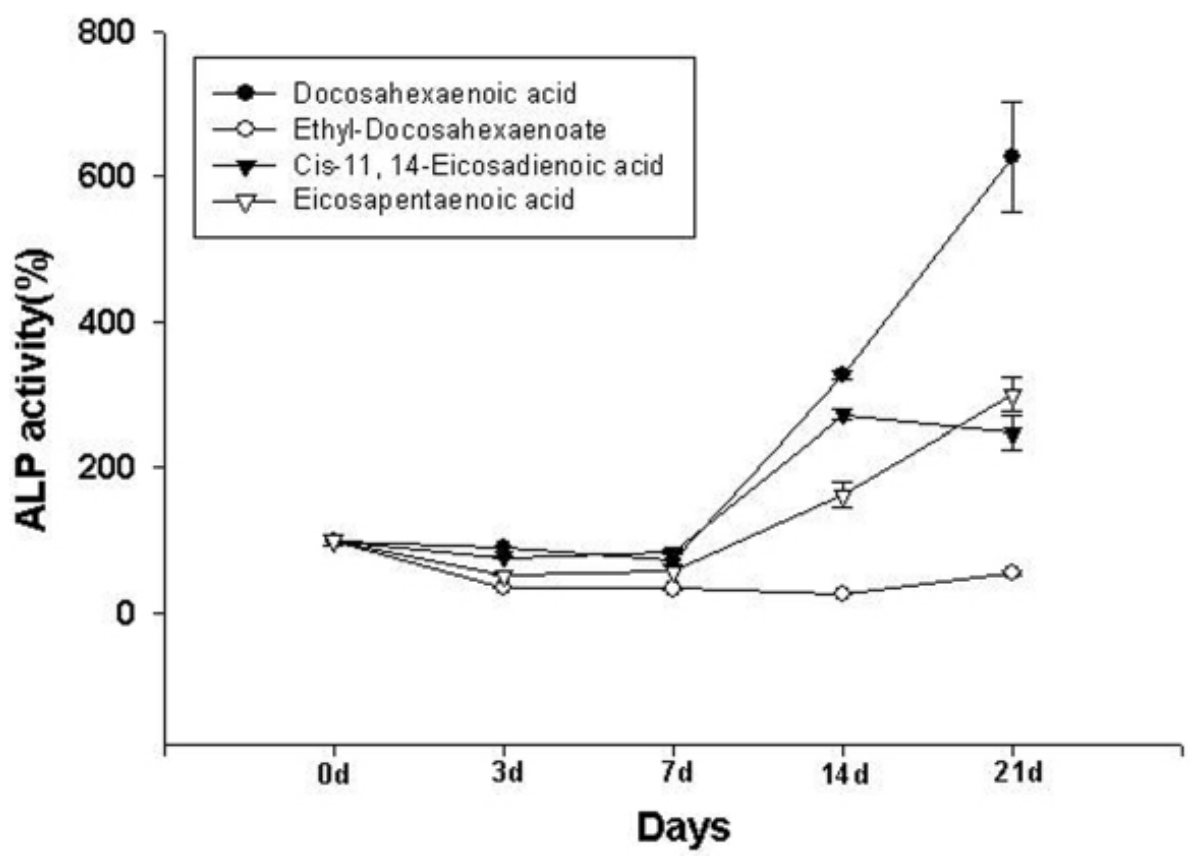

Fig. 5. Effect of 4 PUFAs on the ALP activity during the differentiation of MC3T3-E1 cells. Murine osteoblast MC3T3-E1 were induced to differentiate with osteoblast differentiation medium containing DMEM, 10\% FBS, $10 \mathrm{mM}$ disodium $\beta$-glycerophosphate, and $0.15 \mathrm{mM}$ ascorbic acid in the presence of E-DHA, DHA, Cis-11,14Eicosadienoic acid, and Eicosapentaenoic acid for the indicated times. The cells were harvested, and $50 \mu \mathrm{g}$ of the cell lysates was used to measure the ALP activity at $405 \mathrm{~nm}$. The results are expressed as the mean \pm S.D. of at least three individual experiments. 


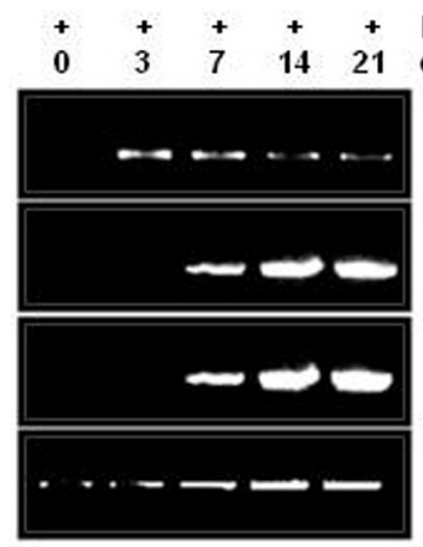

DHA

days

BMP2

OPG

OCN

GAPDH
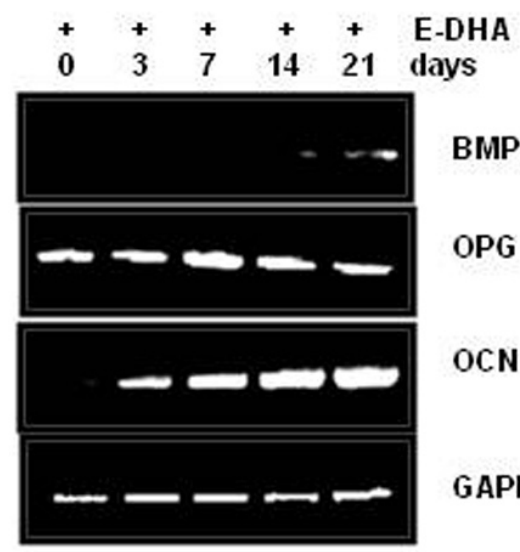

BMP2

OPG

OCN

GAPDH

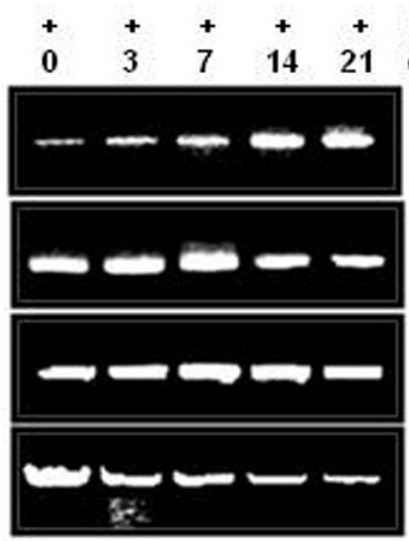

cis-11,14-EDA

days

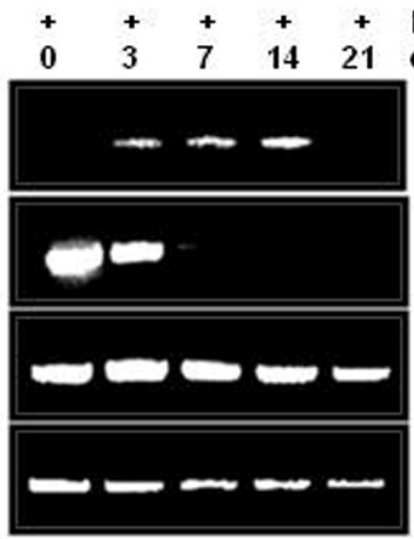

EPA

days

BMP2

BMP2

Fig. 6. Expression profiles of osteoblast specific genes during the differentiation of MC3T3-E1 cells. The MC3T3-E1 cells were cultured for the indicated times and the total RNA was extracted for RT-PCR analysis. RT-PCR was performed with the specific forward and reverse primers for bone morphogenetic preotein 2 (BMP$2)$, osteoprotegerin (OPG), and

GAPDH osteocalcin (OCN). The results are expressed as the mean \pm S.D. of three individual experiments.

clast differentiation in vivo and in vitro (Tachi et al., 2010b). Tachi et al reported that BMP-2 enhances osteoclast differentiation by upregulating the RANKL induced by $1 \alpha, 25$-dihydroxyvitamin $\mathrm{D}_{3}$.

In this study, E-DHA was found to be a much more potent inhibitor of osteoclastogenesis in RANKL-induced RAW264.7 cells than DHA, cis-11, 14-eicosadienoic acid or EPA. E-DHA may exert its inhibitory effect by suppressing the JNK and NF$\kappa \mathrm{B}$ signaling pathways. The inhibitory effect was also correlated with the osteoclast specific genes, such as MMP-9, c-fms and TRAP expression. Interestingly, DHA strongly induced osteoblast differentiation in MC3T3-E1 cells under the present experimental condition. Therefore, these results can explain why a DHA diet induces bone formation but does not inhibit bone resorption in animal experiments.

In summary, E-DHA inhibits osteoclastogenesis significantly via the JNK and NF- $\mathrm{KB}$ signaling pathways, and DHA induces osteoblast differentiation by rapidly inducing BMP-2 in MC3T3-E1 cells. Although additional experiments will be needed to confirm its efficacy in vivo, these results suggest that DHA and E-DHA can be used therapeutically to treat bone diseases, such as osteoporosis and rheumatoid arthritis.

\section{ACKNOWLEDGMENTS}

This study was supported by the Grant of the Korean Min- istry of Education, Science and Technology" (The Regional Core Research Program/Center for Healthcare Technology Development) and by the Korea Science and Engineering Foundation (KOSEF) Grant funded by the Korean Government (MEST) (R01-2008-000-20556-0).

\section{REFERENCES}

Calder, P. C. and Zurier, R. B. (2001) Poryunsaturated fatty acids and rheumatoid arthritis. Curr. Opin. Clin. Nutr. Metab. Care. 4, 115121.

Choi, H. J., Park, Y. R., Nepal, M., Choi, B. Y., Cho, N. P., Choi, S. H., Heo, S. R., Kim, H. S., Yang, M. S. and Soh, Y. (2010) Inhibition of osteoclastogenic differentiation by lkarisoside A in RAW 264.7 cells via JNK and NF-kappaB signaling pathways. Eur. J. Pharmacol. 636, 28-35.

Hudert, C. A., Weylandt, K. H., Lu, Y., Wang, J., Hong, S., Dignass, A., Serhan, C. N. and Kang J. X. (2006) Transgenic mice rich in endogenous omega- 3 fatty acids are protected from colitis. Proc. Natl. Acad. Sci. USA. 103, 11276-11281.

Kobayashi, N., Kadono, Y., Naito, A., Matsumoto, K., Yamamoto, T., Tanaka, S. and Inoue, J. (2001) Segregation of TRAF6-mediated signaling pathways clarifies its role in osteoclastogenesis. EMBO J. 20, 1271-1280.

Lee, S. E., Woo, K. M., Kim, S. Y., Kim, H. M., Kwack, K., Lee, Z. H. and Kim, H. H. (2002) The phosphatidylinositol 3-kinase, p38, and extracellular signal-regulated kinase pathways are involved in osteoclast differentiation. Bone 30, 71-77.

Lee, W. T. (1996) Coloured standard illustrations of Korean plants. pp. 
642. Academy Press, Seoul.

Liu, C., Walter, T. S., Huang, P., Zhang, S., Zhu, X., Wu, Y., Wedderburn, L. R., Tang, P., Owens, R. J., Stuart, D. I., Ren, J. and Gao, B. (2010) Structural and functional insights of RANKL-RANK interaction and signaling. J. Immunol. 184, 6910-6919.

Luo, J. L., Kamata, H. and Karin, M. (2005) IKK/NF-kappaB signaling: balancing life and death--a new approach to cancer therapy. $J$. Clin. Invest. 115, 2625-2632.

Meydani, S. N., Endres, S., Woods, M. M., Goldin, B. R., Soo, C., Morrill-Labrode, A., Dinarello, C. A. and Gorbach, S. L. (1991) Oral (n-3) fatty acid supplementation suppresses cytokine production and lymphocyte proliferation: comparison between young and older women. J. Nutr. 121, 547-555.

Mori, T. A. and Beilin, L. J. (2001) Long-chain omega 3 fatty acid blood lipids and cardiovascular risk reduction. Curr. Opin. Lipidol. 12, 1117.

Mukherjee, A., Wilson, E. M. and Rotwein, P. (2010) Selective signaling by Akt2 promotes bone morphogenetic protein2-mediated osteoblast differentiation. Mol. Cell. Biol. 30, 1018-1027.

Otsuka, E., Notoya, M. and Hagiwara, H. (2003) Treatment of myoblastic C2C12 cells with BMP-2 stimulates vitamin D-induced formation of osteoclasts. Calcif. Tissue Int. 73, 72-77.

Park, C. K., Lee, Y., Chang, E. J., Lee, M. H., Yoon, J. H., Ryu, J. H. and Kim, H. H. (2008) Bavachalcone inhibits osteoclast differentiation through suppression of NFATc1 induction by RANKL. Biochem. Pharmacol. 75, 2175-2182.

Park, Y. R., Eun, J. S., Choi, H. J., Nepal, M., Kim, D. K., Seo, S. Y., Li, R., Moon, W. S., Cho, N. P., Cho, S. D., Bae, T. S., Kim, B. I. and Soh, Y. (2009) Hexane-soluble fraction of the common fig, ficus carica, inhibits osteoclast differentiation in murine bone marrowderived macrophages and RAW 264.7 cells. Korean J. Physiol. Pharmacol. 13, 417-424.

Poulsen, R. C., Firth, E. C., Rigers, C. W., Moughan, P. J. and Kruger M. C. (2007) Specific effects of gamma-linolenic, eicosapentaenoic, and docosahexaenoic ethyl esters on bone post-ovariectomy in rats. Calcif. Tissue Int. 81, 459-471.

Raggatt, L. J. and Partridge, N. C. (2010) Cellular and molecular mechanisms of bone remodeling. J. Biol. Chem. 285(33), 2510325108.

Rahman, M. M., Bhattacharya, A. and Fernandes, G. (2008) Docosahexaenoic acid is more potent inhibitor of osteoclast differentiation in RAW 264.7 cells than eicosapentaenoic acid. J. Cell. Physiol. 214, 201-209

Reddy, S. V., Hundley, J. E., Windle, J. J., Alcantara, O., Linn, R., Leach, R. J., Boldt, D. H. and Roodman, G. D. (1995) Characterization of the mouse tartrate-resistant acid phosphatase (TRAP) gene promoter. J. Bone Miner. Res. 10, 601-606.

Simopoulos, A. P., Kifer, R. R. and Wykes, A. A. (1991) Omega 3 fatty acid: Research advance and support in the field since June 1985(worldwide). World Rev Nutr Diet. 66, 51-71.

Sun, D., Krishnan, A., Zaman K., Lawrence, R., Bhattacharya, A. and Fernandes, G. (2003) Dietary n-3 fatty acids decrease osteoclastogenesis and loss of bone mass in ovariectomizes mice. J. Bone Miner Res. 18, 1206-1216.

Tachi, K., Takami, M., Sato, H., Mochizuki, A., Zhao, B., Miyamoto, Y., Tsukasaki, H., Inoue, T., Shintani, S., Koike, T., Honda, Y., Suzuki, O., Baba, K. and Kamijo, R. (2010a) Enhancement of bone morphogenetic protein-2-inhanced ectopic bone formation by transforming growth factor- $\beta 1$. Tissue Eng. Part $A$. Epub ahead of print.

Tachi, K., Takami, M., Zhao, B., Mochizuki, A., Miyamoto, Y., Inoue, T., Baba, K. and Kamijo, R. (2010b) Bone morphogenetic protein 2 enhances mouse osteoclast differentiation via increased levels of receptor activator of NF-kB ligand expression in osteocblast. Cell Tissue Res. 342, 213-220.

Takayanagi, H., Kim, S., Koga, T., Nishina, H., Isshiki, M., Yoshida, H., Saiura, A., Isobe, M., Yokochi, T., Inoue, J., Wagner, E. F., Mak, T. W., Kodama, T. and Taniguchi, T. (2002) Induction and activation of the transcription factor NFATc1 (NFAT2) integrate RANKL signaling in terminal differentiation of osteoclasts. Dev. Cell 3, 889-901.

Theill, L. E., Boyle, W. J. and Penninger, J. M. (2002) RANK-L and RANK: T cells, bone loss, and mammalian evolution. Annu. Rev. Immunol. 20, 795-823.

Yaqoob, P. and Calder, P. (1995) Effects of dietary lipid manipulation upon inflammatory mediator production by murine macrophages. Cell Immunol. 163, 120-128.

Yoshida, H., Hayashi, S., Kunisada, T., Ogawa, M., Nishikawa, S., Okamura, H., Sudo, T., Shultz, L. D. and Nishikawa, S. (1990) The murine mutation osteopetrosis is in the coding region of the macrophage colony stimulating factor gene. Nature. 345, 442-444.

Zhao, Q., Shao, J., Chen, W. and Li, Y. P. (2007) Osteoclast differentiation and gene regulation. Front Biosci. 12, 2519-2529 